\title{
Exploring EFL Students' Perception of Online Learning via Microsoft Teams: University Level in Indonesia
}

\author{
Ahmad Ridho Rojabi ${ }^{\mathrm{a}, 1, *}$ \\ ${ }^{a}$ IAIN Jember, Indonesia \\ 1 ahmadridhorojabi@gmail.com * \\ * corresponding author
}

\section{ARTICLE INFO}

\section{Article history}

Received 19 June, 2020

Revised 10 August, 2020

Accepted 8 September, 2020

\section{Keywords}

students' perception

online learning

English language teaching

\section{ABSTRACT}

An internet connection has been crucial in the era of globalization to enhance human activities in various activities of economic, culture, defense, and many others, especially in the EFL classroom setting. Microsoft Teams as an innovative online learning platform provides unique features to enhance its potential to help EFL teachers to conduct better interaction as well learning environment in online learning. This research aimed at exploring students' perceptions of online learning via Microsoft Teams. The study was conducted with twenty-eight sixthsemester students at Open University (Universitas Terbuka-UPBJJ Jember). Data were collected by using questionnaires to gain information about the EFL students' perception of online learning via Microsoft Teams. The questionnaire was distributed to the students through Google forms after all materials in online learning had been conducted. The questionnaires data obtained were analyzed descriptively. The finding of the research revealed that online learning via Microsoft Teams is categorized as something new for the students but this interaction and learning environment motivated students in participating online learning, as a result, they can easier to comprehend the learning materials.

This is an open access article under the CC-BY-SA license

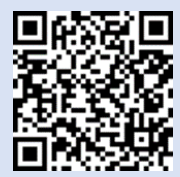

\section{Introduction}

An internet connection has been crucial in the era of globalization to enhance human activities in various activities of economic, culture, defense, and many others (Fallows, 2004). Furthermore, Allen \& Seaman (2017) found that there were approximately six-million students who took part in at least one higher education online course in 2015, compared to 1.6 million in 2002. It means that in the era of globalization, technology is capable of promoting human life, one of which is in the education field. By exploiting technology, teaching and learning activities are now not only carried out in schools, but it can also be carried out in long distances.

As reported by Dorf (2019), educational technologies are classified into learning tools, educational resources, learning environments, as well as learning methods. Firstly, both digital and non-digital technologies used to promote learning through internet connection is defined as learning tools Secondly, educational resources provide textbooks, tutorials, and other learning materials. Thirdly, providing the learners to learn both in conventional as well as in online learning management systems in various locations, contexts, and cultures is defined as a learning environment. Fourthly, exemplifying an action of the specific contents of a subject that may be 
properly understood by learners is defined as a learning method. For instance; drill and practice, memorization, collaborative learning, and competency-based learning. It can be concluded that the learners' experiences covering learner's perceptions, as well as learners' performances of the learning tools, educational resources, learning environment, and methods can be gained through educational technology.

Learning systems by integrating internet connections with teaching and learning processes are identified as online learning systems or virtual learning systems (Bentley et al., 2012). Providing all courses of distance learning exclusively over the internet is called online learning (Nguyen, 2015). In brief, this kind of teaching differs from conventional or face-to-face learning where students are expected to enter a classroom physically. In a face-to-face classroom, some students lose opportunities to communicate, unless they are self-confident, and can respond quickly, whereas online learning provides the learner with the flexibility and offers them with an engaged learning environment. Bakerson et al. (2015) states that in online learning, the learners are offered unique opportunities for an engaging learning environment. In an online learning environment, face to face interaction is replaced by virtual interaction which provides convenience and flexibility (Bower et al., 2015; Hoi et al., 2018; Landrum et al., 2020; Smith et al., 2019). Virtual learning provides unique features of a learning management system, for instance, authoring tools, rubrics, feedback tools, chat discussion, comment field, assignment submission, and files or document sharing.

An online instructor can assess the sense of community by observing who is taking part and who is performing in the group (Tinto, 2009). In line with this statement, Martin et al. (2019) argues that it is important for an online teacher to be enthusiastic and extract resources at their institution by implementing both asynchronous and synchronous learning of a variety of platforms. Moreover, Hamilton (2015) states that in an online digital device, the students teach and learn each other spontaneously, they turn a teacher-directed, technology-based, non-individualized activity into a project that expressed their interests and viewpoints as well as demonstrate creativity and collaboration. In brief, this online learning creates an engaging as well as enjoyable learning by providing unique features to gain better interaction as well as a learning environment.

Hamilton (2015) confirms that instructional technology used by the teacher is more important than the equipment used. The purposes of the activities are to develop background knowledge, model an activity, to read, to demonstrate, to solve a problem, to explore, to review information, to respond to an idea, fee senses, as well as to engage students in critical thinking. Furthermore, identifying the learning objectives and providing the appropriate students' needs in learning is the most important step in designing an online learning environment. The objectives provide all learning objectives, teaching strategies, learning activities, and assessments that are listed on the syllabus (Sewell et al., 2010). Sebastianelli (2015) confirms that learning material was the most important factor for both grasped learning and student satisfaction. Furthermore, teachers should know that what the student does is more important than what they do. To construct a meaningful and valuable user experience, the materials and learning activity in online learning platforms should be useful, usable, desirable, findable, accessible, credible as well as valuable (Dorf, 2019).

In English Language Teaching, EFL lecturers provide the learners integrated skills, namely; listening, speaking, reading, and writing by implementing various methods or strategies to increase the students' motivation and involvement in the teaching and learning process. At university, the English language teaching aim is to improve the student's language skills both oral and written. There are various methods that EFL lecturers may exploit in the classroom based on the students' character and students' needs. The methods provide them to an engaged learning process, improve their language skills as well as develop their critical thinking skills. One of the effective methods is by exploiting online learning. Online learning supports the learners' autonomy and enhance selfdiscipline for their learning progress (Zayapragassarazan, 2020). In sum, online learning is designed to encourage the student's participation, motivation, self-discipline, and learners' autonomy in an online learning environment.

One of the effective online learning platforms is Microsoft Teams, it is a cloud app digital hub that brings conversations, meetings, files and apps together in a single Learning Management System (LMS) (Microsoft, 2018). Microsoft Teams applications can easily be downloaded through desktop and mobile applications, and its features are exploited by people everywhere. Microsoft Teams provides better features like other social media covering chat rooms, collaborative 
discussion, content sharing, and video conferencing (Buchal \& Songsore, 2019; Henderson et al., 2020; Hubbard \& Bailey, 2018; Ilag, 2020; McVey et al., 2019; Tsai, 2018).

Tsai (2018) predicts that Microsoft Teams will exist in advance over the next two years. By the end of 2020, 41\% of organizations expect to use Microsoft Teams globally. Tsai's research covered a survey of 901 respondents from various organizations including small to medium-sized businesses and enterprises. Respondents came from a variety of industries, together with manufacturing, healthcare, non-profits, education, government, and finance. This research is somewhat limited for educational research, however, it provides a type of environment students will experience as they turn into the workplace.

Teachers can post assignments to individuals, small groups, or the full class using the assignment function in Teams (Allison \& Hudson, 2020; Pretorius, 2018). They explained that in their practice they could adjust assignments to everyone in their diverse classroom of learning styles and academic abilities. In brief, the teachers can exploit features provided in Microsoft Teams. The features include scheduling the meeting, sharing invitation links to the students to join the meeting, conducting web conference, interacting in the web conference, sharing files or documents, sharing screen or desktop, communicating in chatting box, changing the role of participants to attendee or presenter, recording web conference, as well as downloading the recording. Materials, students interaction, as well as a learning environment, are the important factors which help students in achieving their learning goal optimally (Fortune et al., 2011). As mentioned earlier, Microsoft Teams as one of the online learning platforms provide those three factors which can be applied in an online learning environment.

One disadvantage in online learning is the inability of the teachers to see the students' body language. There is a missing nonverbal hint expression of confusion on a student's face, for example, or distracted doodling in a notebook that could help them measure understanding. In online learning, the teachers need to take extension time to assess students from the beginning (Bakerson et al., 2015). Another cause of failure in online learning environments is the lack of an arranged schedule, repeatedly studying, disciplined as well as self-motivation (Sun, 2014). It means that teachers need to provide nice facial expressions and body language, good learning materials, and learning instructions to create nice interaction and motivate the learners in participating in an online class.

Some previous studies were conducted to measure the level of satisfaction on students' interaction as well as students' learning environment. According to Fortune et al. (2011), the dimensions of online learning cover learning environment, face to face, technology, learning, preferences, and collaboration. Meanwhile, Gray \& DiLoreto (2016) confirm that course structure/organization, learner interaction, student engagement, instructor presence, and student satisfaction are the appropriate dimensions of online learning. Hence, In this study, measuring student interaction as well as learning environment in online learning are conducted. Considering the above explanations, the researcher is interested to conduct this study to explore the EFL students' perception in online learning via Microsoft Teams. The perceptions cover the students' interaction as well as the learning environment in online learning via Microsoft Teams. Furthermore, the research questions are; (1) How is the students' interaction in online learning via Microsoft Teams? and (2) How is the students' learning environment in online learning via Microsoft Teams?

\section{Research Method}

After finishing the online class via Microsoft Teams, 28 students from undergraduate students pursuing a bachelor degree of early childhood study program in Indonesian Open University, Jember branch were selected by purposive sampling and they were required to complete a questionnaire. A questionnaire survey was given and collected to know the result of students' perceptions. The questionnaire was used to describe students' perception in online learning from 2 aspects of perception: students' interaction as well as students' learning environment. The data were collected from the students by using the questionnaire after finishing the online class via Microsoft Teams. The questionnaire was developed to describe students' perceptions of online leaning for English class. The questionnaire has 16 items of 2 dimensions. The dimension of student interaction was developed by Gray (2016), while learning environment was developed by Fortune (2011). 
The questionnaire contained a 16 five-point Likert format: (5) Strongly Agree, (4) Agree, (3) Neutral, (2) Disagree, and (1) Strongly Disagree which was distributed to know the students' perception in English online class. This instrument was developed by the researcher based on the review of the literature of perception theories. The students responded to the questionnaire once, after finishing all the materials in an online class via Microsoft Teams. All the responses were collected online through the Google Forms website. The validity and reliability of data were processed by using SPSS Software. The validity was tested by using the Pearson correlation method, while reliability was tested by using the Cronbach's alpha method. Furthermore, the questionnaire distributed to the learners was adopted, modified, and translated into the Indonesian language. One expert was involved in editing each item of questionnaire into the Indonesian language. Furthermore, the data obtained from the questionnaire is presented in the form of tables and figures to determine the tendency of students' perceptions related to students' interaction as well as students' learning environment in online learning via Microsoft Teams.

\section{Finding And Discussion}

From the analyzed questionnaire, the following results were obtained, and the results of the validity and reliability, students' perception of students' interactions in online learning are presented in the following tables and figures.

Table 1 . The validity and reliability

\begin{tabular}{cccccccc}
\hline Items & $\begin{array}{c}\text { r }- \\
\text { value }\end{array}$ & sig & $\begin{array}{c}\mathbf{r}- \\
\text { table }\end{array}$ & Conclusion & $\begin{array}{c}\text { Cronbach's } \\
\text { Alpha }\end{array}$ & $\begin{array}{c}\text { Critical } \\
\text { point }\end{array}$ & Conclusion \\
\hline Q1 & 0,770 & 0,000 & 0,374 & Valid & & & \\
Q2 & 0,870 & 0,000 & 0,374 & Valid & & \\
Q3 & 0,879 & 0,000 & 0,374 & Valid & & \\
Q4 & 0,409 & 0,031 & 0,374 & Valid & & \\
Q5 & 0,806 & 0,000 & 0,374 & Valid & & \\
Q6 & 0,795 & 0,000 & 0,374 & Valid & & \\
Q7 & 0,535 & 0,003 & 0,374 & Valid & & \\
Q8 & 0,739 & 0,000 & 0,374 & Valid & 0,956 & & \\
Q9 & 0,896 & 0,000 & 0,374 & Valid & & \\
Q10 & 0,729 & 0,000 & 0,374 & Valid & & \\
Q11 & 0,791 & 0,000 & 0,374 & Valid & & \\
Q12 & 0,582 & 0,001 & 0,374 & Valid & & \\
Q13 & 0,844 & 0,000 & 0,374 & Valid & & \\
Q14 & 0,882 & 0,000 & 0,374 & Valid & & \\
Q15 & 0,891 & 0,000 & 0,374 & Valid & & \\
Q16 & 0,892 & 0,000 & 0,374 & Valid & & & \\
\hline
\end{tabular}

In this study, the validity test was carried out using the Pearson correlation method. If the correlation value ( $\mathrm{r}$-count) obtained is greater than $\mathrm{r}$ table, it is concluded that the question is valid. In the number of samples (N) 28, the value of r-table is 0.374 . Based on the table above, the lowest calculated $\mathrm{r}$ value is 0.409 , namely Q4 and the highest calculated $\mathrm{r}$-value is 0.896 , namely Q9. Because all questions have a calculated $r$ value greater than $r$-table, it can be concluded that all questions are valid.

Meanwhile, the reliability test was carried out using the Cronbach's alpha method. If Cronbach's alpha value is greater than its critical point, which is 0.7 , it is concluded that the variable is reliable. Based on the table above, the Cronbach's alpha value obtained was 0.956. As the value is greater than 0.7 , it can be concluded that the data is reliable. 
Table 2. The number or respondents who took questionnaire on students' interaction in online learning via Microsoft Teams

\begin{tabular}{cclrrrrrrrr}
\hline \multirow{2}{*}{ No } & Score & Criteria & \multicolumn{10}{c}{ Frequency } \\
\cline { 4 - 10 } & & & Item 1 & Item 2 & Item 3 & Item 4 & Item 5 & Item 6 & Item 7 & Item 8 \\
\hline 1 & 5 & strongly agree & 7 & 7 & 2 & 5 & 3 & 3 & 7 & 5 \\
2 & 4 & agree & 12 & 7 & 7 & 18 & 11 & 5 & 15 & 9 \\
3 & 3 & neutral & 2 & 6 & 5 & 2 & 0 & 6 & 4 & 4 \\
4 & 2 & disagree & 7 & 7 & 13 & 3 & 12 & 12 & 2 & 9 \\
5 & 1 & strongly disagree & 0 & 1 & 1 & 0 & 2 & 2 & 0 & 1 \\
\multicolumn{2}{c}{ Total } & & 28 & 28 & 28 & 28 & 28 & 28 & 28 & 28 \\
\hline
\end{tabular}

Table 3. The percentage of the students who took the questionnaire on students' interaction in online learning via Microsoft Teams

\begin{tabular}{|c|c|c|c|c|c|c|c|c|c|c|}
\hline \multirow[t]{2}{*}{ No } & \multirow[t]{2}{*}{ Score } & \multirow[t]{2}{*}{ Criteria } & \multicolumn{8}{|c|}{ Percentage (\%) } \\
\hline & & & Item 1 & Item 2 & Item 3 & Item 4 & Item 5 & Item 6 & Item 7 & Item 8 \\
\hline 1 & 5 & stron & $25.00 \%$ & $25.00 \%$ & $7.10 \%$ & $17.90 \%$ & $10.70 \%$ & $10.70 \%$ & $25.00 \%$ & $17.90 \%$ \\
\hline 2 & 4 & agree & $42.90 \%$ & $25.00 \%$ & $25.00 \%$ & $64.30 \%$ & $39.30 \%$ & $17.90 \%$ & $53.60 \%$ & $32.10 \%$ \\
\hline 5 & 3 & neutra & $7.10 \%$ & $21.40 \%$ & $17.90 \%$ & $7.10 \%$ & $0.00 \%$ & $21.40 \%$ & $14.30 \%$ & $14.30 \%$ \\
\hline 3 & 2 & disag & & 25.0 & 46.4 & & & 42. & $7.10 \%$ & $32.10 \%$ \\
\hline 4 & 1 & $\begin{array}{l}\text { strongly } \\
\text { disagree }\end{array}$ & $0.00 \%$ & $3.60 \%$ & $3.60 \%$ & $0.00 \%$ & $7.10 \%$ & $7.10 \%$ & $0.00 \%$ & $3.60 \%$ \\
\hline \multicolumn{2}{|c|}{ Total } & & $100 \%$ & $100 \%$ & $100 \%$ & $100 \%$ & $100 \%$ & $100 \%$ & $100 \%$ & $100 \%$ \\
\hline
\end{tabular}

The results in the form of the above tables are then analyzed to find out the percentage of students' perceptions of each question item, which is reflected in the figure below.

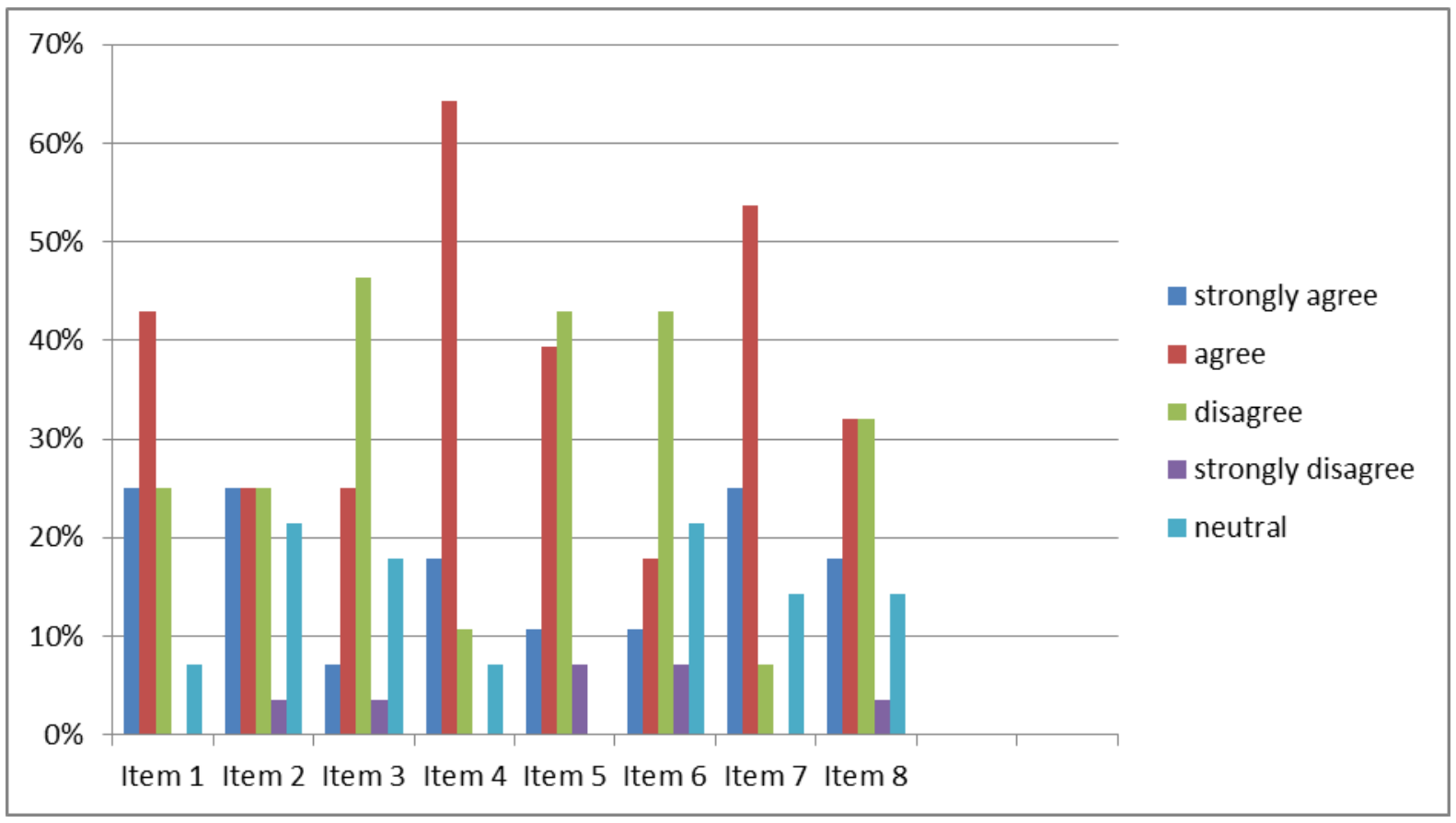

Fig. 1. The percentage of students' perception on students's interaction in online learning via Microsoft Teams 
Based on the above diagram, it illustrates that students show the perception of disagreeing if the students' interaction in online learning supports them in studying. This is proven by several reasons after they gave their response through a questionnaire that they have problems to communicate with both their students and lecturers. The Following is the students' response to each item of the questionnaire.

Item no 1: Online learning makes me easier to interact with the lecturer. From the above question, there are 7 out of 28 students (25\%) who said strongly disagree, 12 students (43\%) who said agree, and 7 students (25\%) who said disagree. This warns us as teachers that interactions between students and lecturers are very important to build communication in the process of teaching and learning. This happens due to the lack of intensity of interaction between students and lecturers in which there is a limited face to face interaction between students and teachers in an online class. This is evident from the students' respond who disagreed that online learning does not make them easier to interact with the lecturer.

Item no 2: Interaction with lecturers becomes closer to online learning. The above question was responded by 7 out of 28 students $(25 \%)$ who said strongly agree, 7 students $(25 \%)$ who said agree and 7 students $(25 \%)$ who said disagree. From the responses, it can be said that some students still find difficulties in getting closer to their lecturers. This is due to the less intensity of face to face interaction between students and lecturers or they are not comfortable with technology to interact.

Item no 3: Expressing the problems faced in online learning to the lecturers is more comfortable than face to face. The above question was responded by 13 out of 28 students (46\%) in a questionnaire who said disagree. That percentage indicates that most students face problems in expressing problems to their lecturers in online learning classes. Things might become worst because if students experience problems dealing with the lecture in an online class, they should consult their problems to their lecturers in order to get the solution.

Item no 4: Miscommunication between lecturers and students often happens in online class. There are 18 out of 28 students $(38.89 \%)$ who said agree. This happens because students and lecturers only interact through written language in English like chat discussion on Microsoft teams and Whatsapp group as well and it often causes miscommunication as there is no face to face communication directly.

Item 5: Online lecture makes interactions between students easier. Besides the problem of interaction with the lecturer, it turns out that online class gives difficulties for students interacting with other students. This is proven by 12 out of 28 students $(46 \%)$ who responded disagree to this question. As teachers, we need to find out a solution. If students face problems dealing with interaction between students, it can influence the learning process. Hence, it can affect the students' learning outcomes.

Item 6: Interaction between students becomes closer in online class. That statement was responded disagree by 12 out of 28 students $(43 \%)$. It means that there is a problem of interaction between students in the online environment as they are not accustomed to student-student interaction virtually. They prefer to have face to face interaction in a conventional class than in online classes.

Item 7: Miscommunication between students often occurs in online classes, for example in conducting the paper of presentation in the group. For this statement, most students responded agree by 15 out of 28 students $(53.60 \%)$. It shows that there is often miscommunication between students in online learning due to the poor signal or the well-preparation in conducting the paper of presentation virtually. In brief, they prefer presenting a paper of presentation in a conventional class to a virtual class.

Item 8: Overcoming complications between students becomes easier in online learning, for example in completing the group paper. For this statement, 9 out of 28 students (32\%) responded agree and 9 out of 28 students (32\%) responded disagree. In online learning, some difficulties in completing group paper could be solved by some students by chatting with their friends through social media, but for other students, they cannot get a solution to overcome complications regarding group paper completion because they are not accustomed to the technology.

Furthermore, the results of students' perceptions of students' learning environment in online learning are presented in the tables and figure below. 
Table 4. The number or respondents who took questionnaire on students' learning environment in online learning via Microsoft Teams

\begin{tabular}{|c|c|c|c|c|c|c|c|c|c|c|}
\hline \multirow[t]{2}{*}{ No } & \multirow[t]{2}{*}{ Score } & \multirow[t]{2}{*}{ Criteria } & \multicolumn{8}{|c|}{ Frequency } \\
\hline & & & Item 1 & Item 2 & Item 3 & Item 4 & Item 5 & Item 6 & Item 7 & Item 8 \\
\hline 1 & 5 & strongly agree & 5 & 5 & 2 & 2 & 3 & 3 & 4 & 4 \\
\hline 2 & 4 & agree & 7 & 13 & 9 & 13 & 5 & 5 & 8 & 3 \\
\hline 5 & 3 & neutral & 6 & 5 & 11 & 9 & 6 & 11 & 8 & 10 \\
\hline 3 & 2 & disagree & 10 & 5 & 6 & 4 & 13 & 9 & 8 & 9 \\
\hline 4 & 1 & strongly disagree & 0 & 0 & 0 & 0 & 1 & 0 & 0 & 2 \\
\hline \multicolumn{2}{|c|}{ Total } & & 28 & 28 & 28 & 28 & 28 & 28 & 28 & 28 \\
\hline
\end{tabular}

Table 5. The percentage of the students who took questionnaire on students' learning environment in online learning via Microsoft Teams

\begin{tabular}{|c|c|c|c|c|c|c|c|c|c|c|}
\hline \multirow{2}{*}{ No } & \multirow{2}{*}{ Score } & \multirow{2}{*}{ Criteria } & \multicolumn{8}{|c|}{ Percentage (\%) } \\
\hline & & & Item 1 & Item 2 & Item 3 & Item 4 & Item 5 & Item 6 & Item 7 & Item 8 \\
\hline 1 & 5 & strongly agree & $17.90 \%$ & $17.90 \%$ & $7.10 \%$ & $7.10 \%$ & $10.70 \%$ & $10.70 \%$ & $14.30 \%$ & $14.30 \%$ \\
\hline 2 & 4 & agree & $25.00 \%$ & $46.40 \%$ & $32.10 \%$ & $46.40 \%$ & $17.90 \%$ & $17.90 \%$ & $28.60 \%$ & $10.70 \%$ \\
\hline 5 & 3 & neutral & $21.40 \%$ & $17.90 \%$ & $39.30 \%$ & $32.10 \%$ & $21.40 \%$ & $39.30 \%$ & $28.60 \%$ & $35.70 \%$ \\
\hline 3 & 2 & disagree & $35.70 \%$ & $17.90 \%$ & $21.40 \%$ & $14.30 \%$ & $46.40 \%$ & $32.10 \%$ & $28.60 \%$ & $32.10 \%$ \\
\hline 4 & 1 & $\begin{array}{l}\text { strongly } \\
\text { disagree }\end{array}$ & $0.00 \%$ & $0.00 \%$ & $0.00 \%$ & $0.00 \%$ & $3.60 \%$ & $0.00 \%$ & $0.00 \%$ & $7.10 \%$ \\
\hline & otal & & $100 \%$ & $100 \%$ & $100 \%$ & $100 \%$ & $100 \%$ & $100 \%$ & $100 \%$ & $100 \%$ \\
\hline
\end{tabular}

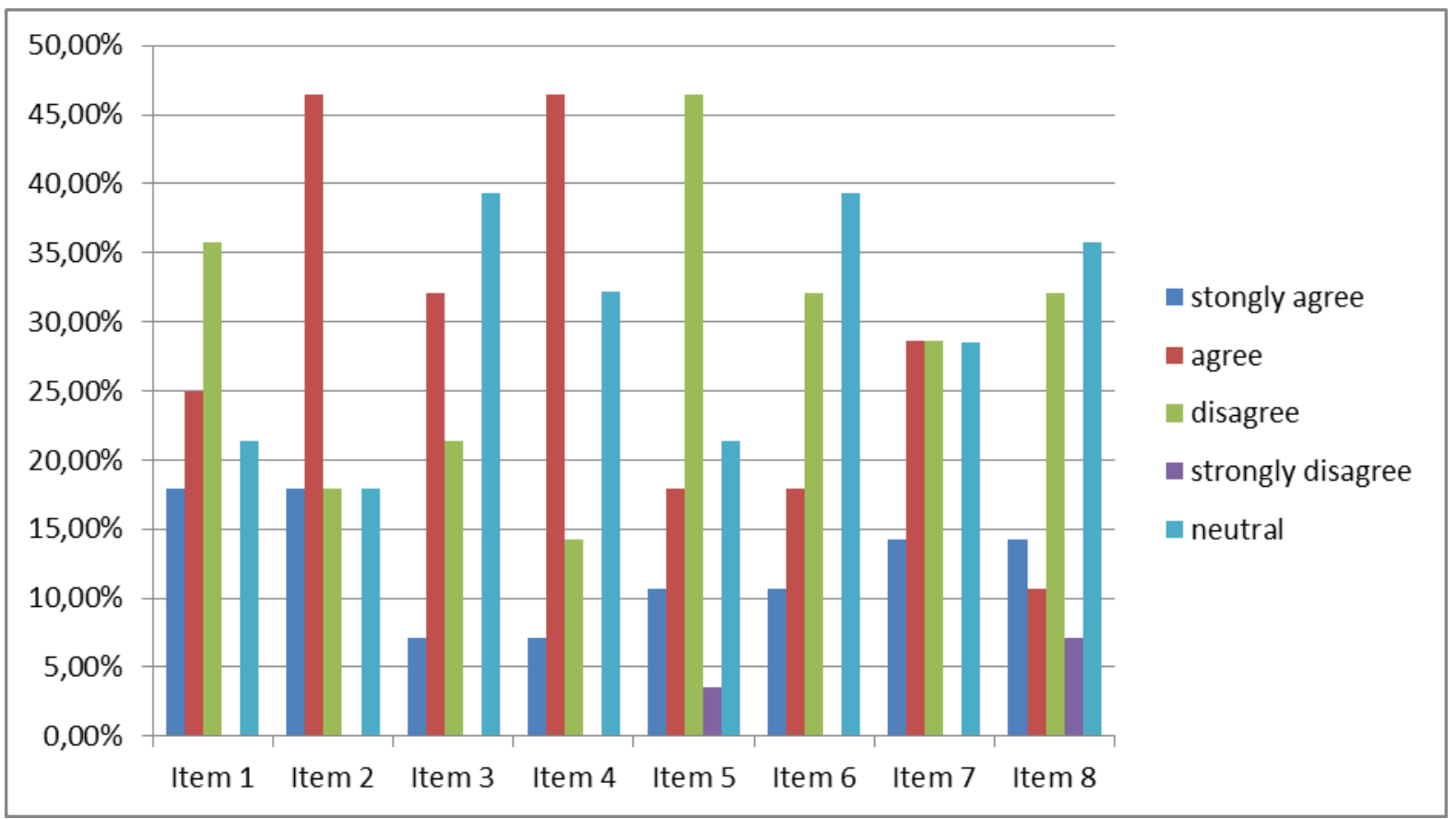

Fig. 2. The percentage of students' perception on students's learning environment in online learning via Microsoft Teams 
Item number 1: Learning environment in online class helps me to understand the materials easier. That statement was responded disagree by 10 out of 28 students $(36 \%)$. It happens due to the students feel that online learning could not support their learning environment comfortably. For example, in online learning, some difficulties in comprehending materials could not be solved easily by some students because they are not accustomed to the technology. Some learners had no selfconfidence to ask questions virtually. In brief, some students are comfortable to have face to face interaction when they get problems with the tasks.

Item number 2: Learning environment in an online class arouses me to learn and understand the materials actively. This statement was responded by 13 out of 28 students $(46 \%)$ of students who responded agree with it. It indicates that students have good enthusiasm for understanding the materials in the online environment due to nice materials, videos, and fun activities collaboratively in an online class.

Item number 3: learning environment in online learning pushes me to take online learning. This statement was responded by 9 out of 28 students (32\%) who agreed with it. They took online classes due to the system of learning during COVID-19 by using an online learning platform, in this case, is by exploiting Microsoft Team. For the first time, it was difficult for them in adapting with the features provided by Microsoft Teams. However, when the lecturer introduced and provided learning materials, and discussions in fun and meaningful tasks in an online class, it motivated them to join and learn English more.

Item number 4: I feel comfortable in answering questions in an online class. This statement was responded by 13 out of 28 students (46\%) who agreed with it. They felt comfortable answering questions from their lecturer due to the easy and interesting materials they got and it is something new and challenging to learn English in online learning. Some students felt comfortable to be volunteers to read the texts provided in the online class as well as to answer some questions or discussions given by the lecturer.

Item number 5: I prefer to learn online to face to face. This statement was responded by 13 out of 28 students $(46.40 \%)$ who disagreed with it. Most students feel that face to face lecture is more comfortable in helping them comprehending the materials easier. Besides, in online learning, they need to have enough data and good signal to support the teaching and learning process. Sometimes, the lecturer or student can get poor signal and they try to re-join the class.

Item number 6: Learning environment in online learning gives me a huge contribution to the study. This statement was responded by 11 out of 28 students (39\%) who said neutral and 9 out of 28 students (32\%) who disagreed with it. The reason why some students said neutral, it is due to the flexibility. In brief, the students can learn English enjoyably at home. For instance, when they got experience in speaking tasks "talking about home", they could easily describe rooms in their house as well as their functions. While other students disagreed with this question, it is due to the sense of discomfort while they were involved in the online learning environment.

Item number 7: Learning environment in online class makes it easier to find my learning needs. This statement was responded by 8 out of 28 students (29\%) who agreed with it. One of the reasons why some students agreed with it is due to the easiness of accessing the materials on the internet. While 8 out of 28 students (29\%) disagreed with it as they prefer face to face interaction in the teaching-learning process. In face to face interaction, they can directly ask some questions when they find difficulties understanding the materials and there are 8 out of 28 students (29\%) who said neutral with it because they had no option, they just followed the class either face to face or online class.

Item number 8: I recommend conducting online learning in the future due to the comfortable learning environment. This statement was responded by 10 out of 28 students (36\%) who said neutral. The reason why some students said neutral because they have already got experience in online learning, and it provides them the benefits as well as challenges. In brief, they have got preparation in learning English either face to face or online class for the future. While 9 out of 28 students (32\%) who disagreed with it because they feel more comfortable when English class is conducted by face to face, for example when they have to study writing or grammar with various patterns of tenses. In face to face interaction, they can create their own sentences or paragraphs well as they can directly be evaluated by the teacher in the classroom. 
From the above results dealing with student's responses towards the learning environment in online learning, it can be debated that the learning environment in online learning does support students in learning. Hence, all supports from teachers, staff as well as parents are needed to enhance the quality of the online learning environment. In line with this, Radovan \& Makovec (2015) confirm that the learning environment becomes one of an essential part of helping students have a better enthusiasm for learning. For this reason, the learning environment should create an impressive atmosphere and motivate students for a better education.

Dealing with student's interaction with the learning environment in online learning, it can be discussed that the student's interaction is also beneficial to support students in online learning. In line with this, Lin \& Lin (2015) confirm that student-students interaction as well as teacher-student interaction should always be constructed to improve communication and discussion of each activity in the process of teaching and learning.

The previous studies conducted by Peterson et al. (2018) and Martin \& Tapp (2019) confirm that the implementation of synchronous learning has facilitated students' interactions and collaborative learning. Hence, they can access all the materials comprehensively. However, based on this current finding, there were still $46 \%$ of students who disagreed that online lecture helps them interacting and collaborating. That weakness of synchronous learning should be solved by the teachers by providing enjoyable activities, and easy tasks so that the learners can engage, interact, as well as collaborate in online learning optimally.

Moreover, Poston et al. (2020) argue that Microsoft Teams will be very beneficial when it starts in a small class, the learners can complete group work of their collaborative paper by exploiting PowerPoint, and the teachers should convince the learners that they already have good understanding of how Teams can be exploited in an online course. It is in line with the current finding that by conducting a small class of 28 students only has resulted in an excellent learning process and learning outcomes. It was revealed that the learners felt comfortable in answering questions, and discussing paper collaboratively due to the interesting materials they got, and they actively engaged to learn English in online learning as it is something new and challenging.

\section{Conclusion}

Based on the findings and discussion, it can be concluded that online class via Microsoft Teams supports the students' learning environment optimally. Most respondents of this study gave their positive perception toward the students' learning environment in an online class. The positive judgment from the respondents came from their experience in online learning by using Microsoft Teams. Furthermore, online learning supports their interaction between student-student interaction, as well as student-teacher interaction.

The current study employed a small sample; the generalizability of these results is limited. However, this study has given a view of students' perception of online learning. Future research should investigate the importance of student interaction, as well as the learning environment in online learning. Additional research could expand the student sample to explore a broader selection of majors and grade levels. Future qualitative analyses could focus on the student's perceptions, students' attitudes, and students' satisfaction of taking online classes as well as the benefits of taking online classes via Microsoft Teams. A focus on student's interaction and learning environment would also be advised to identify the impact of students successful in participating in online learning.

\section{References}

Allen, I. E., \& Seaman, J. (2017). Distance Education Enrollment Report 2017. Digital Learning Compass, 2017. https://doi.org/10.1108/IJEM-02-2014-0018

Allison, N., \& Hudson, J. (2020). Integrating and Sustaining Directed and Self-Directed Learning Through MS Teams and OneNote: Using Microsoft Teams and OneNote to Facilitate Communication, Assignments, and Portfolio Management. BALEAP TEL SIG Webinar, 03 Jun 2020. 
Bakerson, M., Trottier, T., \& Mansfield, M. (2015). Assessment in Online and Blended Learning Environments (S. Koc, X. Liu, \& P. Wachira, (eds.)). Information Age Publishing Inc. https://mafiadoc.com/assessment-in-online-and-blended-learning-_597c73591723ddb28e0735fb.html

Bentley, Y., Selassie, H., \& Shegunshi, A. (2012). Design and Evaluation of Student-focused eLearning. Electronic Journal of E-Learning, $10(1), \quad 12$. https://www.researchgate.net/publication/267262478_Design_and_Evaluation_of_StudentFocused_eLearning

Bower, M., Dalgarno, B., Kennedy, G. E., Lee, M. J., \& Kenney, J. (2015). Design and Implementation Factors in Blended Synchronous Learning Environments: Outcomes from a Cross-case Analysis. Computers \& Education, 86, 1-17. https://doi.org/https://doi.org/10.1016/j.compedu.2015.03.006

Buchal, R., \& Songsore, E. (2019). Using Microsoft Teams To Support Collaborative Knowledge Building in the Context of Sustainability Assessment. Proceedings of the Canadian Engineering Education Association (CEEA), 1-8. https://doi.org/10.24908/pceea.vi0.13882

Dorf, R. C. (2019). Educational Technology. In IEEE Transactions on Education (Vol. 12, Issue 1). https://doi.org/10.1109/TE.1969.4320439

Fallows, D. (2004). The Internet and Daily Life. Pew Research Center's Internet \& American Life Project. https://www.pewresearch.org/internet/2004/08/11/the-internet-and-daily-life/

Fortune, M. F., Spielman, M., \& Pangelinan, D. T. (2011). Students' Perceptions of Online or Face-to-Face Learning and Social Media in Hospitality, Recreation and Tourism. MERLOT Journal of Online Learning and Teaching, 7(1), 1-16. https://www.semanticscholar.org/paper/Students\%27-Perceptionsof-Online-or-Face-to-Face-and-Fortune-Spielman/69ec10415eb160338c5398ea0556ce427d601930

Gray, J. A., \& DiLoreto, M. (2016). The Effects of Student Engagement, Student Satisfaction, and Perceived Learning in Online Learning Environments. NCPEA International Journal of Educational Leadership Preparation, 11(1), 98-119.

Hamilton, B. (2015). Integrating Technology in The Classroom. Tools to Meet the Needs of Every Student. International Society for Technology in https://www.goodreads.com/en/book/show/26088145-integrating-technology-in-the-classroom

Henderson, D., Woodcock, H., Mehta, J., Khan, N., Shivji, V., Richardson, C., Aya, H., Ziser, S., Pollara, G., \& Burns, A. (2020). Keep Calm and Carry on Learning: Using Microsoft Teams to Deliver a Medical Education Programme during the COVID-19 Pandemic. Future Healthcare Journal, 7(3), 1-4. https://doi.org/DOI:10.7861/fhj.2020-0071

Hoi, S. C., Sahoo, D., Lu, J., \& Zhao, P. (2018). Online learning: A Comprehensive Survey. https://arxiv.org/abs/1802.02871

Hubbard, M., \& Bailey, M. J. (2018). Mastering Microsoft Teams. In Mastering Microsoft Teams. https://doi.org/10.1007/978-1-4842-3670-3

Ilag, B. N. (2020). Organization Readiness for Microsoft Teams. Apress, Berkeley, CA. https://doi.org/https://doi.org/10.1007/978-1-4842-5875-0_3

Landrum, B., Bannister, J., Garza, G., \& Rhame, S. (2020). A Class of One: Students' Satisfaction with Online Learning. Journal of Education for Business, 0(0), 1-7. https://doi.org/10.1080/08832323.2020.1757592

Lin, E., \& Lin, C. H. (2015). The Effect of Teacher Student Interaction on Students ' Learning Achievement in Online Tutoring Environment. International Journal of Technical Research and Applications, 22(22), 19-22.

Martin, L., \& Tapp, D. (2019). Teaching with Teams: An introduction to teaching an undergraduate law module using Microsoft Teams. Innovative Practice in Higher Education, 3(3), 58-66. http://eprints.staffs.ac.uk/5613/1/Martin and Tapp 2019.pdf

McVey, M., Edmond, A., \& Montgomery, D. (2019). Supporting Students to Develop their Digital Literacies using Microsoft Teams. ALT Winter Conference 2019, 11-12 Dec 2019. http://eprints.gla.ac.uk/206468/

Microsoft. (2018). Welcome to Microsoft Teams. Microsoft Teams [Online]. https://docs.microsoft.com/enus/microsoftteams/teams-overview

Nguyen, T. (2015). The Effectiveness of Online Learning: Beyond no Significant Difference and Future Horizons. MERLOT Journal of Online Learning and Teaching, 11(2), 309-329. https://jolt.merlot.org/Vol11no2/Nguyen_0615.pdf

Peterson, A. T., Beymer, P. N., \& Putnam, R. T. (2018). Synchronous and Asynchronous Discussions: Effects on Cooperation, Belonging, and affect. Online Learning Journal, 22(4), 7-25. https://doi.org/10.24059/olj.v22i4.1517

Poston, J., Apostel, S., \& Richardson, K. (2020). Using Microsoft Teams to Enhance Engagement and Learning with Any Class: It' s Fun and Easy. Pedagogicon Conference Proceedings, 6, 1-7. https://encompass.eku.edu/pedagogicon 
Pretorius, M. (2018). SharePoint and Assignments. Microsoft Teams for Education. [Online]. https://techcommunity.microsoft.com/t5/Microsoft-Teams-for-Education/MicrosoftTeamsAssignments-and-SharePoint-Documents/td-p/287119

Radovan, M., \& Makovec, D. (2015). Adult Learners' Learning Environment Perceptions and Satisfaction in Formal Education-case Study of Four East-European Countries. International Education Studies, 8(2), 101-112. https://doi.org/https://doi.org/10.5539/ies.v8n2p101

Sebastianelli, R., Swift, C., \& Tamimi, N. (2015). Factors Affecting Perceived Learning, Satisfaction, and Quality in the Online MBA: A Structural Equation Modeling Approach. Journal of Education for Business, 90(6), 296-305. https://doi.org/10.1080/08832323.2015.1038979

Sewell, J., Frith, K., \& Colvin, M. (2010). Online Assessment Strategies: A primer. MERLOT Journal of Online Learning and Teaching, 6(1), 297-305. https://jolt.merlot.org/vol6no1/sewell_0310.pdf

Smith, C., Hoderi, M., \& Mcdermott, W. (2019). A Preliminary Study of Students Perception and Learning from Different Delivery Methods. Academy of Educational Leadership Journal, 23(2), 1C.

Sun, S. (2014). Learner Perspectives on Fully Online Language Learning. Distance Education, 35(1), 18-42. https://doi.org/10.1080/ 01587919.2014.891428

Tinto, V. (2009). Taking student Retention Seriously: Rethinking the First Year of University. FYE Curriculum Design Symposium. http://www.fyecd2009.qut.edu.au/re- sources/ SPE_VincentTinto_5Feb09.pdf.

Tsai, P. (2018). Business Chat Apps in 2018: Top Players and Adoption Plans. The Spiceworks Community. [Online]. https://community.spiceworks.com/blog/3157-business-chat-apps-in-2018-topplayers-andadoption-plans $\% 0 \mathrm{~A}$

Zayapragassarazan, Z. (2020). COVID-19: Strategies for Online Engagement of Remote Learners. Jawaharlal Institute of Postgraduate Medical Education and Research (JIPMER), 9(246), 1-11. https://doi.org/https://doi.org/10.7490/f1000research.1117835.1 